\title{
Preditores de Comportamentos e Competência Acadêmica de Crianças de Famílias Nucleares, Monoparentais e Recasadas
}

\author{
Predictors of Children's Behavior Problems and Academic Competence \\ of Nuclear, Separated and Remarried Families
}

\author{
Vanessa Barbosa Romera Leme*, a \& Edna Maria Marturano ${ }^{\mathrm{b}}$ \\ ${ }^{a}$ Universidade Federal de São Carlos, São Carlos, São Paulo, Brasil \\ $\&{ }^{b}$ Universidade de São Paulo, Ribeirão Preto, São Paulo, Brasil
}

\begin{abstract}
Resumo
Este estudo investigou preditores de habilidades sociais, problemas de comportamento e competência acadêmica de crianças, em um momento sensível do desenvolvimento, isto é, a transição para o primeiro ano do ensino fundamental. Participaram 160 mães de diferentes configurações familiares, cujos filhos estavam matriculados no primeiro ano do ensino fundamental, e 22 professoras das crianças como informantes. Os instrumentos utilizados foram: Inventário de Práticas Parentais; Sistema de Avaliação de Habilidades Sociais; Inventário de Recursos do Ambiente Familiar. Os resultados indicaram que as práticas parentais negativas e a qualidade da relação da criança com o pai biológico foram os melhores preditores dos comportamentos e da competência acadêmica das crianças. A configuração familiar não foi associada aos indicadores de ajustamento infantil focalizados no estudo. Palavras-chave: Relações pais-criança, comportamento infantil, competência acadêmica.
\end{abstract}

\begin{abstract}
This study investigated precursors of children's social skills, behavior problems and academic competence at a sensitive time of development - the transaction to the first grade of elementary school. Participants were 160 mothers from different family structure, with offspring in the first grade of elementary school, and 22 teachers. The instruments used were: Parental Practices Inventory; Social Skills Rating System; and Home Environment Resources Scale. The results indicated that negative parental practices and the quality of biological father-child relationship were the best predictors of children's behavior and academic competence. Family structure was not associated with indicators of child adjustment focused on the study.

Keywords: Parent-child relations, child behavior, academic competence.
\end{abstract}

A família ocidental é marcada atualmente pela diversidade em sua configuração. Famílias formadas por mãe, pai e filhos da primeira união conjugal convivem, nos dias atuais, cada vez mais com arranjos familiares formados após a separação e o recasamento. Estudos de revisão (Amato, 2010; Lansford, 2009; Oliveira, Siqueira, Dell'Aglio, \& Lopes, 2008) indicam divergências quanto à extensão, duração e severidade dos efeitos da separação conjugal e do recasamento sobre dimensões do desenvolvimento dos filhos. Somado a isso, pesquisadores (Amato, 2010; Lansford, 2009) defendem que a separação conjugal e o recasamento não afetam o desenvolvimento infantil per se, mas sim que essas transições aumentam, sobretudo, a probabilidade de os pais e as crianças se depararem com um

* Endereço para correspondência: Rua Frederico Ozanan, 633, Jardim São Vicente, Santa Rita do Passa Quatro, São Paulo, SP, Brasil, 13670-000. E-mail: vanessaromera@ gmail.com.

Pesquisa financiada pela Fundação de Amparo à Pesquisa do Estado de São Paulo (FAPESP; Processo no. 52132-08). conjunto de riscos inter-relacionados que poderiam prejudicar os processos familiares. Esses riscos e as interações entre eles são mediados e moderados, de forma complexa, por diversas variáveis que podem estar relacionadas a importantes indicadores de ajustamento infantil como, por exemplo, competência social e acadêmica e dificuldades comportamentais: (a) tipo de configuração familiar; (b) tempo da transição; (c) estágio desenvolvimental da família e de cada membro da família; (d) personalidade e psicopatologia parental; (e) nível socioeconômico; (f) rede social de apoio; (g) conflito conjugal e práticas parentais; (h) idade, gênero e temperamento dos filhos (Amato, 2010; Hetherington, 2003; Lansford, 2009). Dentre essas variáveis, baseado na Teoria Bioecológica do Desenvolvimento Humano (Bronfenbrenner, 2011), o presente estudo focaliza: (a) práticas parentais; (b) recursos do ambiente familiar; (c) qualidade da relação da criança com o pai.

\section{Práticas Parentais}

As práticas parentais podem ser definidas como um conjunto de estratégias utilizadas pelos pais em situações 
cotidianas para orientar os comportamentos dos filhos e, assim, promover a socialização infantil (Gomide, 2006). Práticas parentais caracterizadas pela expressão de sentimentos positivos, consistência no estabelecimento de regras e limites, envolvimento e monitoria parental das atividades escolares e de lazer dos filhos são relacionadas, muitas vezes, a um repertório de habilidades sociais, a um relacionamento satisfatório com pares e familiares e a um bom desempenho acadêmico em crianças (Amato, 2010; Boas \& Bolsoni-Silva, 2010; Hetherington, 2003; Karreman, Van Tuijl, Van Aken, \& Dekovíc, 2009). Inversamente, práticas coercitivas (baseadas em agressões e ameaças), permissivas (pais que exercem pouco ou nenhum controle diante de comportamentos indesejados dos filhos) e inconsistentes (pais que ora cumprem o que foi estabelecido, ora não) têm sido associadas a dificuldades comportamentais e baixo rendimento acadêmico (Gomide, 2006; Karreman et al., 2009; Lansford, Wager, Bates, Pettit, \& Dodge, 2012).

Segundo Hetherington (2003), as práticas parentais são frequentemente afetadas pelas mudanças no status conjugal entre homens e mulheres com filhos. Para a autora, eventos de vida negativos associados às transições familiares (tais como, conflito conjugal e declínio econômico, no caso da separação e adaptação a um novo membro familiar, no caso do recasamento) parecem contribuir para que pais e mães se engagem em práticas parentais coercitivas, expressem menos afeto, fiquem menos comunicativos e apresentem menos consistência em suas práticas disciplinares (Amato, 2010; Cartwright, 2010; Hetherington, 2003; Potter, 2010; Vélez, Wolchik, Tein, \& Sandler, 2011). Estudos sugerem que as práticas parentais seriam os preditores mais importantes do bem-estar emocional e da adaptação social e escolar da criança cujos pais se separaram e/ou se recasaram (Dunn, 2002; Hetherington, 2003). Assim, a investigação dessa variável parece ser essencial para o entendimento da forma como a criança reage à ruptura conjugal e ao recasamento dos pais.

\section{Recursos do Ambiente Familiar}

Em conjunto com as práticas parentais, como a monitoria parental das atividades escolares e de lazer da criança e o estabelecimento de rotina diária de horários para as atividades infantis, recursos do ambiente da família, tais como acesso a livros, brinquedos e passeios são positivamente associados com bom desempenho acadêmico e com a competência social infantil (Clarke-Stewart, Vandell, McCartney, Owen, \& Booth, 2000; Ferreira \& Barrera, 2010; Trivellato-Ferreira \& Marturano, 2008). Estudos indicam que um ambiente familiar estável, previsível e que favorece a estimulação cognitiva e o desenvolvimento de habilidades sociais das crianças pode prevenir problemas de comportamento externalizantes e hiperativos (Clarke-Stewart et al., 2000; Marturano, Elias, \& Leme, 2012; Potter, 2010). Contudo, nos primeiros anos após a separação conjugal e o recasamento, pode haver maior instabilidade e imprevisibilidade no ambiente familiar, decorrentes de mudanças econômicas, alterações nas funções parentais etc. (Amato, 2010; Dunn, 2002; Lansford, 2009), de modo que as famílias nucleares apresentam mais recursos no ambiente familiar quando comparadas às famílias monoparentais e recasadas (Carlson \& Corcoran, 2001; Chiu, 2007; Clarke-Stewart et al., 2000; Kim, 2004).

Assim, quando controlados os recursos do ambiente familiar, as diferenças entre famílias com e sem história de separação conjugal/recasamento são pequenas ou nulas (Ferreira \& Barrera, 2010; Strohschein, 2005). Levando-se em conta esses dados, é notória a importância dos recursos do ambiente familiar para o ajustamento e o desempenho escolar de crianças, principalmente para aquelas cujas famílias passaram por separação conjugal e recasamento.

\section{Relação da Criança com o Pai Biológico}

Mudanças socioeconômicas e culturais que ocorreram nas últimas décadas, na sociedade ocidental, ocasionaram mudanças na definição de família (Holtzman, 2011) e no status da paternidade (Valente, Medrado, \& Lyra, 2011). O estudo bibliográfico de Valente et al. (2011) acerca da paternidade identificou que o modelo de família patriarcal, centrado na figura masculina, foi gradativamente dividindo espaço com novas formas de famílias que se organizavam em torno, por exemplo, da figura feminina, nas famílias monoparentais, ou mesmo, da figura masculina, tal como a paternidade formada após a ruptura conjugal. Contudo, Valente et al. (2011) concluem que a visão tradicional de paternidade vinculada à dicotomia sexo-gênero e ao estereótipo de uma figura universal de pai ainda é recorrente no saber científico. Paralelamente, pesquisas sobre a paternidade hoje indicam que há maior expressão de afeto e participação ativa do pai nos cuidados dos filhos (Valente et al., 2011; Staudt \& Wagner, 2011). Estudos têm encontrado correlações positivas entre o envolvimento paterno e o desenvolvimento acadêmico e de habilidades sociais dos filhos, especialmente quando esses se encontram em idade escolar (Cia \& Barham, 2009; Eymann, Busaniche, Llera, Cunto, \& Wahren, 2009).

No contexto das alterações verificadas no papel do pai, as transições familiares destacaram-se ao criar tipos de interações pais-filhos que podem interferir no desenvolvimento social e cognitivo infantil (Dantas, Jablonski, \& Féres-Carneiro, 2004). De forma geral, a literatura sinaliza um afastamento paterno e a reprodução dos papéis tradicionais do homem e da mulher após a separação e o recasamento (Dunn, 2002; Grzybowski, 2011; Moura \& Matos, 2008). Segundo Amato, Meyers e Emery (2009), os primeiros estudos sobre a relação da criança com o pai após a separação conjugal enfatizaram a frequência do contato entre pai-filho. Contudo, pesquisas mais recentes têm sublinhado a importância da qualidade da relação do pai com a criança para o seu bom desenvolvimento após a separação e o recasamento (Amato, et al., 2009; Sandler, Miles, Cookston, \& Braver, 2008). Dessa forma, uma importante tarefa e desafio que se coloca às novas formas de famílias é manter a coparentalidade após a separação 
Leme, V. B. R. \& Marturano, E. M. (2014). Preditores de Comportamentos e Competência Acadêmica de Crianças de Famílias Nucleares, Monoparentais e Recasadas.

conjugal (Grzybowski, 2011; Troilo \& Coleman, 2012). Quando pais e mães conseguem superar conflitos conjugais após a separação, mantêm uma boa comunicação e negociação quanto às responsabilidades nos cuidados dos filhos e apresentam consistência em suas práticas educativas, os filhos têm maior probabilidade de internalizar as regras socialmente aceitas (Grzybowski, 2011). Além disso, a coparentalidade é uma oportunidade de os filhos pequenos aprenderem com os pais habilidades de negociação, comunicação, respeito e resolução de problemas (Amato, 2010; Lansford, 2009), especialmente em fases significativas do desenvolvimento, como a transição para o ensino fundamental.

\section{Teoria Bioecológica do Desenvolvimento Humano (TBDH) e Transição para o Primeiro Ano do Ensino Fundamental}

Para a TBDH (Bronfenbrenner, 2011), o desenvolvimento infantil é interdependente e afetado pelos processos proximais (tais como as práticas parentais) que ocorrem nos contextos imediatos (microssistemas) em que a criança participa ativamente (por exemplo, a família e a escola que juntos formam o messossistema), pelas suas características biopsicológicas (tais como habilidades sociais e dificuldades comportamentais), pelos contextos mais externos que a criança não frequenta (como o trabalho dos pais - exossistema), pelas ideologias, valores e crenças compartilhados na cultura (macrossistema) e pelas mudanças que ocorrem ao longo do tempo (cronossistema). Num olhar bioecológico, o ingresso da criança no primeiro ano do ensino fundamental pode ser "lido" como uma transição ecológica, isto é, quando ocorre uma mudança de papel, ambiente ou ambos (Bronfenbrenner, 1979/2002). É um período de imprevisibilidade que pode gerar estresse e ansiedade para a criança (Marturano, 2008).

Estudos indicam que a transição para o primeiro ano pode ser facilitada quando há estabilidade no ambiente familiar (Ackerman, Kogos, Youngstrom, Schoff, \& Izard, 1999), suporte parental e os pais utilizam práticas educativas positivas (Johnson, Cowan, \& Cowan, 1999; Trivellato-Ferreira \& Marturano, 2008). Não obstante a separação e o recasamento parental parecem afetar justamente esses processos familiares (Amato, 2010; Cadima, McWillian, \& Leal, 2010; Hetherington, 2003) que poderiam contribuir para uma transição bem sucedida ao primeiro ano. Por sua vez, o fato de o desenvolvimento da criança não ser influenciado apenas por aqueles ambientes em que ela participa diretamente confere-lhe, na perspectiva bioecológica, um carácter sistêmico e dinâmico. Assim, o desenvolvimento é passível de múltiplas trajetórias e é impossível afirmar a priori que as transições familiares resultarão em dificuldades comportamentais nos filhos manifestadas nos contextos da família e da escola. A partir dessas considerações, este estudo tem por objetivo investigar preditores de habilidades sociais, problemas de comportamento e competência acadêmica de crianças de famílias nucleares, monoparentais e recasadas, em um momento sensível do desenvolvimento, isto é, a transição para o primeiro ano do ensino fundamental. Tem-se por hipótese geral que as práticas parentais e os recursos do ambiente da família têm maior efeito preditivo que o tipo de configuração familiar sobre os comportamentos e a competência acadêmica das crianças.

\section{Método}

Foi realizado um estudo preditivo com desenho transversal em amostra de conveniência (não probabilística) composta por 160 mães (33 de famílias nucleares, 33 separadas há menos de três anos, 33 separadas há mais de três anos, 31 recasadas há menos de três anos e 30 recasadas há mais de três anos), cujos filhos passavam pela transição para o primeiro ano do ensino fundamental. $O$ número de participantes em cada grupo atendeu a um requisito para análise estatística paramétrica, no pressuposto de que em amostras com 25-30 sujeitos a distribuição da média amostral é próxima à normal (Marôco, 2011). As crianças frequentavam cinco escolas municipais em cidade do interior do Estado de São Paulo. As mães (idade média 32,1 anos, $D P=5,9)$ tinham, em média, 8,6 anos de escolaridade $(D P=2,8)$. As crianças ( 77 meninas e 83 meninos) tinham idade entre 6 e 7 anos. As famílias do estudo encontravam-se nas classes C1 e C2 (renda familiar entre R $\$ 1204,00$ e $\mathrm{R} \$ 1541,00$ ), o que corresponde a $48 \%$ da distribuição da população do Estado (Associação Brasileira de Empresas de Pesquisa [ABEP], 2010).

Para participar do estudo, a mãe deveria residir com a criança, visto que iria avaliar suas práticas parentais nas interações cotidianas com a criança e a relação desta com o pai biológico. Critérios de inclusão referendados na literatura (Amato, 2010; Dunn, 2002; Hetherington, 2003) foram estabelecidos para definir as famílias nucleares, monoparentais e recasadas, assim como a recência da separação ou do recasamento: (a) Famílias nucleares: quando a mãe biológica da criança coabitava numa união civil ou por consenso com o pai biológico da criança desde o nascimento desta. (b) Famílias monoparentais em transição recente: quando a mãe biológica da criança não coabitava com o pai biológico da criança ou com outro companheiro. A mãe da criança deveria ter coabitado com o ex-cônjuge (pai biológico da criança) em uma união civil ou por consenso por no mínimo um ano, a contar do nascimento da criança e deveria estar separada há pelo menos seis meses e no máximo há três anos. (c) Famílias monoparentais estáveis: quando a mãe biológica da criança não coabitava com o pai biológico da criança ou com outro companheiro. A mãe da criança deveria ter coabitado com o ex-cônjuge (pai biológico da criança) em uma união civil ou por consenso por no mínimo um ano, a contar do nascimento da criança e deveria estar separada há mais de três anos. (d) Famílias recasadas em transição recente: quando a mãe biológica da criança coabitava numa união 
civil ou por consenso com outro parceiro, que não era o pai biológico da criança. A mãe deveria ter coabitado com o ex-cônjuge, pai biológico da criança, durante no mínimo um ano, a contar do nascimento da criança e deveria estar recasada há pelo menos um ano e há menos de três anos. (e) Famílias recasadas estáveis: quando a mãe biológica coabitava com outro parceiro, que não era o pai biológico da criança. A mãe deveria ter coabitado com o ex-cônjuge, pai biológico da criança, durante no mínimo um ano, a contar do nascimento da criança e deveria estar recasada há mais de três anos.

Também participaram do estudo 22 professoras (idade média 41 anos, $D P=10,48$ ) do primeiro ano das cinco escolas. As professoras lecionavam apenas no ensino regular, em média há 12 anos. Todas haviam concluído o ensino superior.

\section{Instrumentos}

Inventário de Práticas Parentais (IPP). Trata-se de um instrumento destinado a pais e mães de filhos em idade escolar, construído por Benetti e Balbinotti (2003). O inventário é composto por 29 itens que avaliam práticas parentais referentes a cinco dimensões: Social (exemplo: "participa de jogos e atividades com o filho"); Educação (exemplo: "Eu ensino meu filho as matérias que ele não entende na escola"); Disciplina (exemplo: "Eu grito com meu filho quando ele faz alguma coisa errada"); Afeto (exemplo: "Eu abraço e beijo meu filho"); Responsabilidade (exemplo: "Eu posso estar ocupada, mas meu filho sabe aonde me encontrar se precisar de algo"). Os participantes devem estimar o grau de ocorrência das práticas parentais, numa escala Likert de 1 (nunca) a 5 (sempre). Grzybowski (2007), ao avaliar as práticas parentais de 234 pais e mães separados com filhos em idade escolar, encontrou índice de consistência interna global igual a 0,90 (alfa de Cronbach). No presente estudo, foram obtidos índices de consistência interna que variaram de 0,64 a 0,83 para as cinco dimensões avaliadas.

Sistema de Avaliação de Habilidades Sociais (Social Skills Rating System, SSRS-BR). Avalia o repertório de habilidades sociais, problemas de comportamento e competência acadêmica das crianças. Criado por Greshan e Elliott (1990), foi validado para o Brasil (SSRS-BR; Bandeira, Del Prette, Del Prette, \& Magalhães, 2009). As versões para pais e professores são bastante semelhantes. A frequência com que a criança apresenta habilidades sociais (por exemplo, cooperação, autocontrole e assertividade), problemas de comportamento (hiperatividade, externalizante e internalizante) e competência acadêmica (versão apenas para professores) é avaliada em escalas de três pontos (nunca, às vezes, sempre). Na amostra de validação, foram encontrados índices aceitáveis de consistência interna e estabilidade temporal. No presente estudo, em que foram utilizadas as versões de pais (alfa entre 0,83 e 0,86 na amostra de validação) e professores (alfa entre 0,91 e 0,94 na amostra de validação), foram encontrados valores de alfa acima de 0,73 nas duas versões, exceto para o componente Internalizantes da escala de comportamentos problemáticos, versão para pais $(\alpha=0,37)$; assim, esta dimensão não foi incluída nas análises.

Inventário de Recursos do Ambiente Familiar (RAF). É um instrumento desenvolvido por Marturano (2006) para investigar os recursos do ambiente familiar que podem contribuir para o desempenho acadêmico nos anos do ensino fundamental. É composto por dez tópicos: (a) O que a criança faz quando não está na escola; (b) Quais os passeios que a criança realizou nos últimos 12 meses; (c) Há atividades programadas que a criança realiza regularmente; (d) Quais atividades os pais desenvolvem com a criança em casa; (e) Quais os brinquedos que ela tem ou já teve; (f) Há jornais e revistas na sua casa; (g) Há livros na sua casa; (h) Alguém em casa acompanha a criança nos afazeres da escola; (i) Seu filho tem hora certa para; (j) Sua família costuma estar reunida. O inventário é aplicado sob a forma de uma entrevista semiestruturada, onde cada tópico é apresentado oralmente. Ferriolli, Marturano e Puntel (2007) ao aplicar o RAF com mães $(N=100)$ de diferentes configurações familiares, cujos filhos tinham idade entre seis e 12 anos, encontraram índice satisfatório de consistência interna $(\alpha=0,83)$. Para a presente amostra o instrumento apresentou confiabilidade aceitável $(\alpha=0,73)$.

Questionário de Caracterização Familiar e Critério de Classificação Econômica. O Questionário de Caracterização Familiar foi elaborado para este estudo para obter informações sobre a criança, a mãe e a configuração familiar. A qualidade da relação da mãe com o ex-cônjuge foi avaliada por meio da pergunta: "Como é a sua relação com seu ex-cônjuge (pai da criança)?", e a qualidade da relação da criança com o pai biógico foi avaliada por meio da pergunta "Como é a relação da criança com o pai?" Ambas as perguntas feitas às mães tinham as opções de respostas: ótima, boa, mais ou menos, ruim ou péssima. $\mathrm{Na}$ análise de dados, foram atribuídos valores de 1 (péssima) a 5 (ótima). Foi também empregado o Questionário de Classificação Econômica Brasil (ABEP, 2010; http://www. abep.org/) que avalia o nível socioeconômico e permite a estratificação das famílias em cinco classes: A (subdividida em A1 e A2), B (subdividida em B1 e B2), C, D e E. No Brasil, a classificação contempla, em ordem decrescente de poder aquisitivo: A1, A2, B1, B2, C1, C2, D, E.

\section{Procedimento}

O projeto foi aprovado por Comitê de Ética em Pesquisa, de acordo com o Processo n ${ }^{\circ}$ 379/2008-2008.1.449.59.7. Para a seleção da amostra, após assinarem o Termo de Consentimento Livre e Esclarecido (TCLE), as professoras foram solicitadas a mandar, no caderno de recado dos alunos, um comunicado às mães, solicitando um meio de contato e perguntando o seu estado civil (casada, separada ou recasada). Em posse das respostas, a pesquisadora entrava em contato com as mães, por telefone, para verificar 
Leme, V. B. R. \& Marturano, E. M. (2014). Preditores de Comportamentos e Competência Acadêmica de Crianças de Famílias Nucleares, Monoparentais e Recasadas.

o interesse em participar do estudo e conferir os critérios de inclusão. Em seguida, havendo interesse das mães, a pesquisadora marcava um encontro para a assinatura do TCLE e para a aplicação dos instrumentos. A coleta de dados com as mães foi realizada nas suas residências ou locais de trabalho. Mediante a assinatura do TCLE, a pesquisadora aplicava os instrumentos: Questionário de Caracterização Familiar, IPP, SSRS-BR, RAF e Questionário Classificação Econômica Brasil. Após a coleta com as mães, a pesquisadora agendou com cada professora um horário para que avaliasse as crianças. A pesquisadora aplicou com cada professora, individualmente, o SSRS-BR, na própria escola, após o término das aulas.

A análise de dados foi realizada no programa SPSS e compreendeu três etapas: (a) exploração das diferenças relacionadas à escolaridade das mães, renda famíliar (Anova one- way) e gênero das crianças (teste do qui-quadrado); (b) cálculo de correlação entre as variáveis do estudo (coeficiente $r$ de Pearson). Para interpretar os valores dos coeficientes de correlação, utilizou-se a classificação proposta por Ajzen e Fishbein (1998): < $0,30=$ correlação fraca; $\geq 0,30$ e $<0,50=$ moderada; $>$ $0,50=$ forte; (c) análise de regressão linear múltipla com método stepwise. Os pressupostos de regressão múltipla (normalidade, independência e multicolinearidade) foram testados e confirmados antes de se realizarem as análises. Foram consideradas como variáveis dependentes (VD) as habilidades sociais, os problemas de comportamento e a competência acadêmica, e como variáveis independentes (VI) o tipo de família, práticas parentais, recursos do ambiente familiar, qualidade da relação da mãe com o pai biológico da criança, qualidade da relação da criança com o pai biológico. Foram criadas quatro variáveis dummy em substituição à VD não métrica tipo de família (nuclear, monoparental recente, monoparental estável, recasada recente e recasada estável).

Para testar os preditores dos comportamentos e da competência acadêmica procedeu-se a dois conjuntos de análises. O primeiro foi realizado com todos os tipos de famílias $(N=160)$ e o segundo, para investigar a influência do preditor "qualidade da relação da criança com o pai biológico", foi realizado sem a família nuclear $(N=127)$. Cada conjunto de análises foi testado com dois modelos de regressão em separado para cada VD ${ }^{1}$. O Modelo 1 teve como VI: práticas parentais positivas (dimensões Social, Educação, Afeto e Responsabilidade), práticas parentais negativas (dimensão Disciplina), recursos do ambiente familiar, qualidade da relação da mãe com o pai biológico da criança e qualidade da relação da criança com o pai biológico. No Modelo 2, as variáveis indicadas como preditores significativos no Modelo 1 foram novamente testadas, com a inclusão da variável preditora tipo de

\footnotetext{
Realizaram-se duas análises de regressão para cada variável dependente devido ao tamanho da amostra ( $N$ =160). Segundo Marôco (2011), para cada variável independente é preciso ter no mínimo 30 sujeitos.
}

família. Esse modelo foi testado duas vezes, com e sem o grupo de famílias nucleares. As análises de regressão foram realizadas paras as avaliações de mães e professoras. Análises comparativas indicaram ausência de diferença entre os tipos de família para as variáveis gênero das crianças $\left(\chi^{2}=0,22 ; p=0,63\right)$, renda familiar $(F=2,24 ; \mathrm{p}=0,86) \mathrm{e}$ escolaridade materna $(F=1,07 ; p=0,14)$, pelo que essas não foram incluídas nas análises de regressão.

\section{Resultados}

A Tabela 1 apresenta as correlações entre as variáveis do estudo. Os resultados indicam diversas correlações significativas, a maioria fraca ou moderada (Ajzen \& Fishbein, 1998), entre as variáveis da criança e os preditores investigados. Chama a atenção que as variáveis presentes no ambiente familiar correlacionam com a maioria dos indicadores de ajustamento infantil presentes no contexto escolar.

Os resultados das análises de regressão com todas as famílias são apresentados na Tabela 2. Foram encontrados resultados semelhantes nos modelos de previsão propostos para o conjunto de análises de regressão que incluiu todas as famílias e para o que excluiu a família nuclear. Contudo, nas análises de regressão sem a família nuclear, a variável qualidade da relação da criança com o pai biológico passou a ser o principal preditor de competência acadêmica, com um aumento no seu poder de predição, de $2 \%$ para $7 \%$ da variância.

Nota-se, na Tabela 2, que os modelos finais preditivos, para as avaliações das mães, apresentam valores altamente significativos nos coeficientes de determinação ( $R^{2}$ Ajustado entre 0,50 e 0,61 ) e incluem como preditores: práticas parentais positivas e negativas; família recasada recente; recursos do ambiente familiar. Para as avaliações das professoras, os resultados indicam que práticas parentais negativas e qualidade da relação criança-pai biológico responderam por pequena fração da variância nos resultados de habilidades sociais, problemas de comportamento e competência acadêmica $\left(R^{2}\right.$ Ajustado entre 0,09 e 0,17$)$.

\section{Discussão}

Com base na Teoria Bioecológica do Desenvolvimento Humano (Bronfenbrenner, 2011), este estudo investigou preditores de habilidades sociais, problemas de comportamento e competência acadêmica de crianças de famílias nucleares, monoparentais e recasadas, num momento sensível do desenvolvimento, isto é, a transição para o primeiro ano do ensino fundamental. As práticas parentais, positivas ou negativas, apareceram na explicação da variação de todos os indicadores de ajustamento infantil, segundo as avaliações das mães e das professoras. Além disso, foram as variáveis com maior peso na predição dos resultados. Esses resultados encontram apoio na literatura, haja vista que as estratégias que as mães e 
Psicologia: Reflexão e Crítica, 27(1), 153-162.

Tabela 1

Correlações entre as Variáveis do Ambiente das Familias e os Indicadores de Ajustamento das Crianças

\begin{tabular}{|c|c|c|c|c|c|c|c|c|c|c|c|}
\hline Variáveis & 1 & 2 & 3 & 4 & 5 & 6 & 7 & 8 & 9 & 10 & 11 \\
\hline 1. Tipo de família & - & $-0,28 * *$ & 0,14 & $-0,12$ & $-0,46^{* *}$ & $-0,41 * *$ & $-0,14$ & 0,15 & $-0,02$ & $0,16^{*}$ & $-0,03$ \\
\hline 2. IPP - positivas & & - & $-0,55 * *$ & $0,66 * *$ & $0,31 * *$ & $0,32 * *$ & $0,63 * *$ & $-0,65 * *$ & $0,16^{*}$ & $-0,22 * *$ & $0,15^{*}$ \\
\hline 3. IPP - negativas & & & - & $-0,33 * *$ & $-0,19 *$ & $-0,27 * *$ & $-0,59 * *$ & $0,71 * *$ & $-0,33 * *$ & $0,36 * *$ & $-0,27 * *$ \\
\hline 4. RAF & & & & - & $0,25 * *$ & $0,25 * *$ & $0,47 * *$ & $-0,49 * *$ & 0,12 & $-0,16^{* *}$ & 0,14 \\
\hline 5. QR - mãe - pai & & & & & - & $0,74 * *$ & $0,24 * *$ & $-0,29 * *$ & $-0,19 * *$ & $-0,25^{* *}$ & 0,15 \\
\hline 6. QR - criança - pai & & & & & & - & $0,31 * *$ & $-0,34 * *$ & $0,27 * *$ & $-0,31 * *$ & $0,24 * *$ \\
\hline 7. HS - mães & & & & & & & - & $-0,72 * *$ & $0,29 * *$ & $-0,27^{* *}$ & $0,18^{* *}$ \\
\hline 8. PC - mães & & & & & & & & - & $-0,31 * *$ & $0,34 * *$ & $-0,27 * *$ \\
\hline 9. HS - professores & & & & & & & & & - & $-0,66 * *$ & $0,68 * *$ \\
\hline 10. PC - professores & & & & & & & & & & - & $-0,49 * *$ \\
\hline 11. CA - professores & & & & & & & & & & & - \\
\hline
\end{tabular}

Nota . IPP - positivas = Inventário de Práticas Parentais Positivas; IPP - negativas = Inventário de Práticas Parentais Negativas; RAF = Inventário de Recursos do Ambiente Familiar; QR - mãe - pai = Qualidade da relação da mãe com o pai da criança; QR - criança - pai = Qualidade da relação da criança com o pai; HS - mães/professores = Habilidades Sociais do Sistema de Avaliação de Habilidades Sociais (SRSS-BR), segundo as avaliações das mães e das professoras; PC - mães/professores = Problemas de Comportamento do SRSS-BR, segundo as avaliações das mães e das professoras; CA = Competência Acadêmica do SRSS-BR, segundo as avaliações das professoras.

$* p \leq 0,05 ; * * \leq \leq 0,01$.

Tabela 2

Sumário dos Resultados dos Conjuntos de Análises de Regressão com todas as Famílias (N=160): Valores para os Modelos 2

\begin{tabular}{|c|c|c|c|c|c|c|}
\hline Variáveis dependentes & Preditores & $B$ & ЕР $B$ & $\beta$ & $\Delta R^{2}$ & Total $R^{2}$ \\
\hline \multirow{3}{*}{$\begin{array}{l}\text { Habilidades sociais - } \\
\text { avaliação das mães }\end{array}$} & Práticas parentais positivas & 0,51 & 0,07 & 0,45 & $0,40^{* *}$ & \multirow{3}{*}{0,50} \\
\hline & Práticas parentais negativas & $-0,94$ & 0,18 & $-0,34$ & $0,48^{* *}$ & \\
\hline & Família recasada em transição recente & 4,24 & 1,81 & 0,13 & $0,02 *$ & \\
\hline \multirow[b]{2}{*}{$\begin{array}{l}\text { Habilidades sociais - } \\
\text { avaliação das professoras }\end{array}$} & Práticas parentais negativas & $-0,60$ & 0,16 & $-0,27$ & $0,10 * *$ & \multirow[b]{2}{*}{0,13} \\
\hline & $\begin{array}{l}\text { Qualidade da relação da criança com } \\
\text { o pai biológico }\end{array}$ & 1,91 & 0,76 & 0,19 & $0,03 *$ & \\
\hline \multirow{3}{*}{$\begin{array}{l}\text { Problemas de } \\
\text { comportamento - } \\
\text { avaliação das mães }\end{array}$} & Práticas parentais negativas & 0,66 & 0,07 & 0,52 & $0,51 * *$ & \multirow{3}{*}{0,61} \\
\hline & Práticas parentais positivas & $-0,13$ & 0,04 & $-0,26$ & $0,60 * *$ & \\
\hline & Recursos do ambiente familiar & $-0,09$ & 0,04 & $-0,15$ & $0,01 *$ & \\
\hline \multirow{2}{*}{$\begin{array}{l}\text { Problemas de } \\
\text { comportamento - } \\
\text { avaliação das professoras }\end{array}$} & Práticas parentais negativas & 0,43 & 0,10 & 0,29 & $0,12 * *$ & \multirow[b]{2}{*}{0,17} \\
\hline & $\begin{array}{l}\text { Qualidade da relação da criança com } \\
\text { o pai biológico }\end{array}$ & $-1,48$ & 0,49 & $-0,22$ & $0,05 *$ & \\
\hline \multirow{2}{*}{$\begin{array}{l}\text { Competência acadêmica - } \\
\text { avaliação das professoras }\end{array}$} & Práticas parentais negativas & $-0,46$ & 0,16 & $-0,22$ & $0,07 * *$ & \multirow[b]{2}{*}{0,09} \\
\hline & $\begin{array}{l}\text { Qualidade da relação da criança com } \\
\text { o pai biológico }\end{array}$ & 1,68 & 0,74 & 0,18 & $0,02 *$ & \\
\hline
\end{tabular}

$* p \leq 0,05 ; * * p \leq 0,01$. 
Leme, V. B. R. \& Marturano, E. M. (2014). Preditores de Comportamentos e Competência Acadêmica de Crianças de Famílias Nucleares, Monoparentais e Recasadas.

os pais usam para socializar os filhos são relacionadas tanto ao bom desenvolvimento social infantil, quanto ao surgimento de dificuldades comportamentais, seja em famílias nucleares (Gomide, 2006; Karreman et al., 2009; Lansford et al., 2012), seja em famílias monoparentais e recasadas (Amato, 2010; Boas \& Bolsoni-Silva, 2010; Hetherington, 2003).

Chama a atenção que variações nos resultados das habilidades sociais, problemas de comportamento e competência acadêmica, avaliados pelas professoras, foram preditas por práticas parentais negativas e não por práticas parentais positivas. Por um lado, esse resultado era esperado segundo a literatura que elucida que práticas parentais baseadas em uso de agressão verbal e/ou física, ameaças, falta de consistência dos pais em estabelecer limites aos filhos são fortemente correlacionadas com dificuldades comportamentais, sócioemocionais e com baixo rendimento acadêmico no ambiente escolar (Gomide, 2006; Karreman et al., 2009; Lansford et al., 2012). $\mathrm{O}$ fato de as mães separadas e recasadas ficarem menos afetuosas, comunicativas e envolvidas com os filhos, conforme indicam estudos (Amato, 2010; Cartwright, 2010; Hetherington, 2003; Potter, 2010; Vélez et al., 2011), pode ajudar a explicar a maior influência das práticas parentais negativas que das positivas, principalmente quando se considera que as crianças do estudo estavam passando por uma transição ecológica (Bronfenbrenner, 1979/2002). Assim, pode-se supor em relação às crianças de mães separadas e recasadas que elas sejam mais afetadas pelas práticas parentais negativas que pelas positivas, e isso se reflita no ambiente escolar.

O primeiro ano do ensino fundamental é um exemplo de transição ecológica que requer que um conjunto de tarefas desenvolvimentais como, por exemplo, ter bom rendimento acadêmico, se dar bem com os colegas e seguir regras de convívio social, seja realizado para que a criança se adapte no novo contexto (Masten \& Coastworth, 1998). Assim, pesquisas encontraram correlações positivas entre a adaptação da criança ao novo ambiente escolar e as práticas parentais positivas, tais como suporte e monitoria parental das atividades escolares e de lazer dos filhos (Johnson et al., 1999; Trivellato-Ferreira \& Marturano, 2008), bem como um ambiente familiar coeso e estável (Ackerman et al., 1999; Marturano, 2008; Potter, 2010). Entretanto, as transições familiares geralmente afetam negativamente essas práticas parentais positivas (Amato, 2010; Dunn, 2002; Lansford, 2009) e podem, portanto, dificultar a realização das tarefas desenvolvimentais requeridas na transição para o primeiro ano do ensino fundamental. Portanto, os resultados parecem sugerir que os efeitos da separação conjugal e do recasamento podem ser potencializados quando tanto as famílias, quanto as crianças vivenciam ao mesmo tempo uma transição ecológica. Nesse sentido, algumas pesquisas evidenciaram que, controlando a qualidade das práticas parentais, atenuam-se os efeitos negativos das transições familiares nas relações entre pais e filhos e no desenvolvimento sócioemocional das crianças (Amato 2010; Hetherington, 2003; Strohschein, 2005). Assim, não seria a transição familiar per se que estaria relacionada aos desafios presentes no ambiente familiar, mas sim as mudanças nos processos familiares.

Nos resultados, os recursos do ambiente familiar explicaram variações nos problemas de comportamento das crianças, avaliados pelas mães. Foram encontradas associações negativas entre os recursos do ambiente familiar e os problemas de comportamento hiperativos e externalizantes das crianças. Esses achados são corroborados por estudos que demonstraram que o acesso a livros e brinquedos, passeios que a criança realiza, monitoria parental das atividades escolares e de lazer dos filhos e estabelecimento de horários para as atividades das crianças são associados negativamente com problemas de comportamento e dificuldades escolares apresentados por crianças (Clarke-Stewart et al., 2000; Ferreira \& Barrera, 2010; Marturano et al., 2012; Potter, 2010). Tais resultados são coerentes como a Teoria Bioecológica, pois segundo Bronfenbrenner (1979/2002, 2011), um ambiente familiar rico em estímulos pode aumentar a frequência de processos proximais que contribuem para o desenvolvimento de competências, tais como as habilidades sociais, que podem funcionar como fator de proteção para dificuldades comportamentais (Barreto, Freitas, \& Del Prette, 2012).

Mesmo após a exclusão da família nuclear dos modelos de análises de regressão, a qualidade da relação da criança com o pai biológico apareceu como preditor na explicação da variação de todos os indicadores de ajustamento infantil avaliados pelas professoras. Por um lado, esse resultado era esperado já que é corroborado por estudos que encontraram que a qualidade da relação com o pai está relacionada positivamente com o repertório de habilidades sociais e com um bom rendimento acadêmico infantil, além de prevenir problemas de comportamento (Cia \& Barham, 2009; Eymann et al., 2009). Por outro, chama a atenção o fato de a qualidade da relação da criança com o pai biológico ter-se associado apenas à competência acadêmica e aos comportamentos exibidos na escola.

A compreensão desse resultado pode ser clareada ao ser analisada em conjunto com resultados de pesquisas que demonstraram que, após a separação conjugal, há uma tendência de afastamento entre pais e filhos (Dunn, 2002; Moura \& Matos, 2008), o que se intensifica com o recasamento dos pais e/ou das mães (Dunn, 2002; Troilo \& Coleman, 2012). A par com esse dado, deve-se lembrar que as crianças que participaram do estudo passavam pela transição para o primeiro ano do ensino fundamental. A literatura indica que, nesse momento do desenvolvimento, a criança se beneficia do auxílio do pai com as novas demandas provenientes do ambiente escolar (Cia \& Barham, 2009; Eymann et al., 2009). Se a qualidade da relação com o pai é relevante para o desempenho e a adaptação da criança à escola, é plausível supor que em fases de transição escolar esse vínculo se torne ainda mais importante 
como fonte de suporte para o enfrentamento dos desafios emergentes. Contudo, as crianças das famílias separadas ou recasadas têm, conforme sinaliza literatura (Dunn, 2002; Grzybowski, 2011; Moura \& Matos, 2008), menos chance de contar com esse apoio devido ao afastamento do pai após a separação conjugal. Pode-se inferir, então, que o efeito da relação com o pai tenha sido amplificado pela conjunção de dois fatores: menor acesso ao suporte do pai em alguns grupos e maior demanda generalizada por esse apoio, devido à transição escolar. Isso ajudaria a explicar a eficiência da qualidade da relação da criança com o pai biológico na adaptação da criança ao ambiente escolar. A qualidade da relação da mãe com pai biológico da criança não foi indicada pelos resultados como um preditor dos comportamentos e da competência acadêmica das crianças. Contudo, a qualidade do relacionamento entre os ex-cônjuges pode contribuir tanto com o envolvimento paterno, quanto com o exercício da coparentalidade, o que, por sua vez, reflete na adaptação da criança à separação conjugal e ao recasamento (Sandler et al., 2008).

Contrariando a hipótese inicial, a família recasada em transição recente foi indicada como um preditor das habilidades sociais das crianças, segundo as avaliações das mães. É possível que o aumento da satisfação conjugal que ocorre nos primeiros anos do recasamento (honeymoon), identificado por Hetherington (1993), contribua para que as mães estabeleçam interações mais afetuosas com os filhos, e isso se correlacione positivamente com as habilidades sociais das crianças expressas no ambiente da família. De forma complementar, considerando que a qualidade da relação conjugal pode afetar a qualidade da relação pais-filhos (Amato et al., 2009; Sobolewski \& King, 2005), pode-se supor também que a satisfação conjugal influencie positivamente o humor da mulher o que, por sua vez, contribuiria para uma percepção mais positiva do comportamento dos filhos. Esses resultados sugerem que o modo como a configuração familiar impacta no desenvolvimento infantil ainda é uma questão aberta à investigação. Portanto, pode-se concluir, a partir da análise dos resultados, que os indicadores de ajustamento infantil focalizados no estudo são mais associados aos processos proximais (tais como práticas parentais e qualidades da relação pais-filhos), que à configuração familiar per se. Assim, acredita-se que é possível, mas não deixa de ser o maior desafio encontrado pelas famílias que rompem com o modelo nuclear de organização familiar, proporcionar aos filhos, após ruptura da conjugalidade parental, condições de vivenciarem interações positivas com ambos os progenitores (Grzybowski, 2011).

\section{Considerações Finais}

Esse estudo apresenta algumas limitações que devem ser consideradas na análise dos resultados. Primeiramente, a qualidade da relação da criança com o pai biológico foi avaliada pela percepção da mãe e não do filho e do pai.
Estudiosos das transições familiares destacam a importância em se investigar as impressões dos filhos e dos pais no que diz respeito à separação conjugal e ao recasamento, as quais podem ser divergentes da percepção materna. Segundo, o estudo utilizou um delineamento transversal e correlacional. Metodologia longitudinal poderia ser útil para avaliar mudanças e continuidades dos padrões de relacionamento entre as crianças e mães/pais. Terceiro, a competência acadêmica da criança foi avaliada por um instrumento de medida comparativa que se baseava nas percepções das professoras. Outros instrumentos, com avaliação objetiva de desempenho, poderiam ser utilizados. Por fim, foram selecionados, com base na literatura revisada, alguns dos possíveis preditores dos comportamentos e da competência acadêmica das crianças. Assim, nenhuma conclusão pode ser tirada sobre a relevância relativa das variáveis do contexto familiar.

Algumas implicações dos resultados devem ser destacadas. As variáveis proximais, cuja supremacia foi estabelecida nas análises de regressão (as práticas parentais, a qualidade da relação da criança com o pai biológico e os recursos do ambiente familiar), são passíveis de intervenção psicólogica e mesmo de programas de saúde pública. $\mathrm{O}$ estudo reitera a importância de as agências governamentais e os centros de atendimento psicológico proporcionarem às famílias monoparentais e recasadas espaços para discutir e implementar a coparentalidade após a ruptura conjugal. Como demonstrado no estudo, a relação com o pai biológico parece interferir no bem-estar psicológico da criança. Pesquisas e intervenções educacionais precisam dissiminar as vantagens da mediação familiar e da guarda compartilhada, que podem evitar a alienação parental.

No que diz respeito às constribuições do estudo, a pesquisa possibilitou uma visão diferenciada dos efeitos de preditores encontrados nos contextos familiar e escolar sobre os comportamentos e a competência acadêmica de crianças de diferentes configurações familiares. Entretanto, os valores baixos dos coeficientes de regressão no ajustamento dos modelos propostos para o contexto escolar indicam que as variáveis explicativas investigadas participam modestamente na explicação da variabilidade do funcionamento das crianças na escola. Portanto, outras variáveis devem ser incluídas em estudos de predição futuros. Além disso, o foco na transição para o primeiro ano foi uma estratégia metodológica que deve ser destacada no estudo. Os resultados obtidos, consistentes e compatíveis com a literatura, apesar das limitações assinaladas em parágrafos precedentes, mostram que o delineamento foi sensível na indicação dos preditores dos comportamentos e da competência acadêmica das crianças. Isso se evidencia quando se verifica que variáveis recorrentemente indicadas na literatura como afetadas pela separação e pelo recasamento parental, isto é, as práticas parentais e a qualidade da relação da criança com o pai biológico, sobressaem como preditores de ajustamento das crianças, seja no microssistema da família, seja no microssistema da escola. 
Leme, V. B. R. \& Marturano, E. M. (2014). Preditores de Comportamentos e Competência Acadêmica de Crianças de Famílias Nucleares, Monoparentais e Recasadas.

\section{Referências}

Ackerman, B. P., Kogos, J., Youngstrom, E., Schoff, K., \& Izard, C. (1999). Family instability and the problem behavior of children from economically disadvantaged families. Developmental Psychology, 35(1), 258-268.

Ajzen, J., \& Fishbein, M. (1998). Overview. In J. Ajzen \& M. Fishbein (Eds.), Understanding attitudes and predicting social behavior. Englewood Cliffs, NJ: Prentice-Hall.

Amato, P. R. (2010). Research on divorce: Continuing trends and new developments. Journal of Marriage and Family, 72(3), 650-666.

Amato, P. R., Meyers, C. E., \& Emery, R. E. (2009). Changes in nonresident father-child contact from 1976 to 2002. Family Relations, 58, 41-53.

Associação Brasileira de Empresas de Pesquisa. (2010). Critério de classificação econômica Brasil, 2010. Dados com base no levantamento sócioeconômico, IBOPE, 2000. Recuperado em 17 junho, 2010, de http://www.abep.org.br

Bandeira, M., Del Prette, Z. A. P., Del Prette, A., \& Magalhães, T. (2009). Validação das Escalas de Habilidades Sociais, Comportamentos Problemáticos e Competência Acadêmica (SSRS-BR) para o ensino fundamental. Psicologia: Teoria e Pesquisa, 25(2), 271-282.

Barreto, S. O., Freitas, L. C., \& Del Prette, Z. A. P. (2012) Habilidades sociais na comorbidade entre dificuldade de aprendizagem e problemas de comportamento: Uma avaliação multimodal. Psico (Porto Alegre), 42(4), 503-510.

Benetti, S. P. da C., \& Balbinotti, M. A. (2003). A elaboração e estudo de propriedades psicométricas do Inventário de Práticas Parentais. Psico-USF, 8(2), 103-113.

Boas, A. C. V. V., \& Bolsoni-Silva, A. T. (2010). Habilidades sociais educativas de mães separadas e sua relação com comportamento de pré-escolares. Psico-USF, 15(3), 301310.

Bronfenbrenner, U. (2002). A ecologia do desenvolvimento humano: Experimentos naturais e planejados (M. A. V. Veronese, Trad.). Porto Alegre, RS: Artmed. (Original publicado em 1979)

Bronfenbrenner, U. (2011). Bioecologia do desenvolvimento humano: Tornando os seres humanos mais humanos (A. de Carvalho-Barreto, Trad.). Porto Alegre, RS: Artmed.

Cadima, J., McWilliam, R. A., \& Leal, T. (2010). Environmental risk factors and children's literacy skills during the transition to elementary school. International Journal of Behavioral Developmental, 34(1), 24-33.

Carlson, M. J., \& Corcoran, M. E. (2001). Family structure and children's behavior and cognitive outcomes. Journal of Marriage and Family, 63, 779-792.

Cartwright, C. (2010). An exploratory investigation of parenting practices in stepfamilies. New Zealand Journal of Psychology, 39(1), 57-64.

Chiu, M. M. (2007). Families, economies, cultures, and science achievement in 41 countries: Country-, school-, and student-level analyses. Journal of Family Psychology, 21(3), 510519.

Cia, F., \& Barham, E. J. (2009). O envolvimento paterno e o desenvolvimento social de crianças iniciando as atividades escolares. Psicologia em Estudo, 14(1), 67-74.

Clarke-Stewart, K. A., Vandell, D. L., McCartney, K., Owen, M. T., \& Booth, C. (2000). Effects of parental separation and divorce on very young children. Journal of Family Psychology, 14, 304-326.
Dantas, C., Jablonski, B., \& Féres-Carneiro, T. (2004). Paternidade: Considerações sobre as relações pais-filhos após a separação conjugal. Paidéia (Ribeirão Preto), 14(29), 347-357.

Dunn, J. (2002). The adjustment of children in stepfamilies: Lessons from community studies. Child and Adolescent Mental Health, 7, 154-161.

Eymann, A., Busaniche, J., Llera, J., Cunto, C. de, \& Wahren, C. (2009). Impacto da separação sobre a qualidade de vida de crianças em idade escolar. Jornal de Pediatria, 85(6), 547-552.

Ferreira, S. H. de A., \& Barrera, S. D. (2010). Ambiente familiar e aprendizagem escolar em alunos da educação infantil. Psico (Porto Alegre), 41(4), 462-472.

Ferriolli, S. H. T., Marturano, E. M., \& Puntel, L. P. (2007). Contexto familiar e problemas de saúde mental infantil no Programa Saúde da Família. Revista de Saúde Pública, 41(2), 251-259.

Gomide, P. I. C. (2006). Inventário de Estilos Parentais: Modelo teórico, manual de aplicação, apuração e interpretação. Petrópolis, RJ: Editora Vozes.

Greshan, F., \& Elliott, S. (1990). Social Skills System: Manual. Circle Pines, MN: American Guidance Service.

Grzybowski, L. S. (2011). Ser pai e ser mãe: Como compartilhar a tarefa educativa após o divórcio? In A. Wagner (Ed.), Desafios psicossociais da família comtemporânea: Pesquisas e reflexões (pp. 19-35). Porto Alegre, RS: Artmed.

Grzybowski, L. S. (2007). Parentalidade em tempo de mudanças. Desvelando o envolvimento parental após o fim do casamento (Tese de doutorado, Pontifícia Universidade Católica do Rio Grande do Sul, Porto Alegre, RS, Brasil).

Hetherington, E. M. (1993). An overview of the Virginia longitudinal study of divorce and remarriage with a focus on early adolescence. Journal of Family Psychology, 2(1), 39-56.

Hetherington, E. M. (2003). Intimate pathways: Changing patterns in close personal relationships across time. Family Relations, 52, 318-331.

Holtzman, M. (2011). Nonmarital unions, family definitions and custody decision making. Family Relations, 60, 617-632.

Johnson, V. K., Cowan, P. A., \& Cowan, C. P. (1999). Children's classroom behavior: The unique contribution of family organization. Journal of Family Psychology, 13(3), 355-371.

Karreman, A., Van Tuijl, C., Van Aken, M. A. G., \& Dekovíc, M. (2009). Predicting young children's externalizing problems: Interactions among effortful control, parenting, and child gender. Merrill-Palmer Quarterly, 55(2), 111-134.

Kim, H.-J. (2004). Family resources and children's academic performance. Children and Youth Services Review, 26, 529536.

Lansford, J. E. (2009). Parental divorce and children's adjustment Perspectives on Psychological Science, 4(2), 140-152.

Lansford, J. E., Wager, L. B., Bates, J. B., Pettit, G. S., \& Dodge, K. A. (2012). Forms of spanking and children's externalizing behaviors. Family Relations, 61, 224-236.

Marôco, J. (2011). Análise estatística com a utilização do SPSS (5. ed.). Lisboa, Portugal: ReportNumber.

Marturano, E. M. (2006). O inventário de recursos do ambiente familiar. Psicologia: Reflexão e Crítica, 19(3), 498-506.

Marturano, E. M. (2008). Tensões cotidianas na transição da primeira série: Um enfoque de desenvolvimento. Psicologia em Estudo, 13(1), 77-85.

Marturano, E. M., Elias, L. C. dos S., \& Leme, V. B. R. (2012). A família e o desenvolvimento do escolar. In L. E. Melchiori, O. M. P. R. Rodrigues, \& A. C. B. Maia (Eds.), Família e 
crianças: Reflexões teórico-práticas sobre os cuidados com as crianças (pp. 137-153). Curitiba, PR: Juruá.

Masten, A. S., \& Coastworth, J. D. (1998). The development of competence in favorable and unfavorable environments: Lessons from research on successful children. American Psychologist, 53(2), 205-220.

Moura, O., \& Matos, P. M. (2008). Vinculação aos pais, divórcio e conflito interparental em adolescentes. Psicologia (Lisboa), 22(2), 127-152.

Oliveira, D. de, Siqueira, A. C., Dell'Aglio, D. D., \& Lopes, R. de C. S. (2008). Impacto das configurações familiares no desenvolvimento de crianças e adolescentes: Uma revisão da produção científica. Interação em Psicologia, 12(1), 87-98.

Potter, D. (2010). Psychosocial well-being and the relationship between divorce and children's academic achievement. Journal of Marriage and Family 72(8), 933-946.

Sandler, L., Miles, J., Cookston, J., \& Braver, S. (2008). Effects of father and mother parenting on children's mental health in high and low conflict divorces. Family Court Review, 46, 282-296.

Sobolewski, J. M., \& King, V. (2005). The importance of the coparental relationship for nonresident fathers' ties to children. Journal of Marriage and Family, 67, 1196-1212

Staudt, A. C. P., \& Wagner, A. (2011). A vivência da paternidade em tempos de diversidade: Uma visão transcultural. In A. Wagner (Ed.), Desafios psicossociais da familia comtemporânea: Pesquisas e reflexões (pp. 99-111). Porto Alegre, RS: Artmed.

Strohschein, L. (2005). Parental divorce and child mental health trajectories. Journal of Marriage and Family, 67, 1286-1300.

Trivellato-Ferreira, M. De. C., \& Marturano, E. M. (2008). Recursos da criança, da família e da escola predizem competência na transição da $1^{\mathrm{a}}$ série. Revista Interamericana de Psicología, 42(2), 549-558.

Troilo, J., \& Coleman, M. (2012). Full-time, part-time full-time, and part-time fathers: Father identities following divorce. Family Relations, 61, 601-614.

Valente, M. B., Medrado, B., \& Lyra, J. (2011). Ciência como dispositivo de produção da paternidade: Análise de produções científicas brasileiras. Athena Digital, 11(2), 57-72.

Vélez, C. E., Wolchik, S. A., Tein, J., \& Sandler, I. (2011). Protecting children from the consequences of divorce: A longitudinal study of the effects of parenting on children's coping processes. Child Development, 82(1), 244-257. 